\title{
Evaluation of a cardiovascular education intervention with motivational text messaging among West African immigrants
}

\author{
Abstract \\ Background: West African Immigrants (WAIs) in the United States (U. S.) are a vulnerable \\ group for cardiovascular disease (CVD), yet few intervention studies have been conducted \\ for CVD risk reduction. The purpose of this study was to evaluate a CVD prevention \\ education program plus motivational text messaging among AWIs. Objectives were to \\ a. Examine CVD health knowledge, behavior, confidence levels in preparing \\ heart healthy foods, and readiness to change behavior between a CV education \\ intervention and motivational text messaging (MTM) and a standard education \\ intervention (SEI). \\ b. Determine differences in these areas between the two groups.
}

Method: This quasi experimental study was conducted in a faith-based organization in the southwestern U.S. over a 10 weeks period. Adult AWIs, aged 18-74 years were recruited. Participants were randomized either to the MTM or the SEI. Both groups received CVD risk factor education (2-hour sessions weekly for 10 weeks). The MTM group received motivational text messaging twice weekly during the study period.

Results: Seventy-five participants were enrolled. Fifty one percent $(n=38)$ participants completed the intervention. Forty seven percent $(\mathrm{n}=16)$ were in the MTM group and $53 \%(n=22)$ were in the SEI group. Each group demonstrated statistically significant improvement in pre-post intervention in CVD risk factor knowledge $(\mathrm{p}=<0.000)$, behavior $(p<0.000)$, confidence level in preparing healthy food $(p<0.000)$, and readiness to change behavior $(\mathrm{p}=0.001)$. There were no differences between groups in CVD risk factor knowledge $(\mathrm{p}=.92)$, behavior $(\mathrm{p}=.81)$, confidence in preparing healthy food $(\mathrm{p}=.50)$ and readiness to change $(\mathrm{p}=.99)$.

Conclusion: Although our sample size was small, motivational text messaging did not appear to make a difference from the standard education intervention. More studies are needed with larger sample sizes to determine best practice for CVD prevention among WAIs.

Keywords: education intervention, hypertension, dysglycemia, dyslipidemia, obesity, knowledge, behavior, gender, urban versus rural communities, geographic regions, exercise
Volume 6 Issue 5 - 2019

Solomon EA,' Wadas TM'

Capstone College of Nursing, University of Alabama, USA

Correspondence: Theresa MWadas, Capstone College of Nursing, University of Alabama, USA,

Email twadas@ua.edu

Received: September 27, 2019 | Published: October 09, 2019
Abbreviations: WAIs, west african immigrants; BMI, body mass index; BCL, blood cholesterol levels; SEI, standard education intervention

\section{Introduction}

Although West African Immigrants (WAIs) make up a small percentage of the immigrant population in the United States (U.S.), their overall numbers are growing, doubling every decade since 1970.1 AWIs includes individuals from Nigeria, Ghana, Togo, and Tanzania. The American Community Survey 2015 revealed WAIs in the U.S. account for 327, 000 from Nigeria, 155,000 from Ghana, 28,000 from Tanzania, and 22,000 from Togo. ${ }^{1}$ WAIs were previously thought to develop CVD and/or risk factors such as diabetes type 2 (DMT2) only after migrating to the U.S. ${ }^{2}$ However, more recent findings demonstrate cardiometabolic syndrome (CMS), (a constellation of. hypertension, dysglycemia, dyslipidemia, and obesity) is prevalent in west Africa. ${ }^{2}$ In fact, WAIs were found to have worse CMS than African Americans. ${ }^{2}$ Moreover, many WAI are undiagnosed prior to U.S. arrival and are unaware they have CVD risk factors or CMS. ${ }^{3}$ Thus, WAIs are a vulnerable population for CVD, particularly in the areas of CVD risk knowledge and behavior.

\section{CVD risk knowledge and behavior}

CVD is the second leading cause of overall death in Africa and the leading cause of death for individuals over 30 years of age. ${ }^{4} \mathrm{CVD}$ risk factor knowledge and behaviors differ pending on gender, urban versus rural communities, and differing African geographic regions CVD risk factor awareness, treatment, and control is low in most countries in Africa. ${ }^{4-6}$ The majority of AWIs adults are unfamiliar with CVD risk factor knowledge and behaviors. ${ }^{46}$ The lack of knowledge and awareness related to CVD risk factors has been found among WAIs with large percentages being unfamiliar with body mass index (BMI) 
or ideal target readings of blood pressure (BP), blood sugar (BS), and blood cholesterol levels (BCL) $)^{4,6-8}$ Evidence evaluating CMS showed WAI men were more likely to rapidly gain weight in the first two years after arrival to the U.S., less likely to exercise, and due lack of health insurance showed worse CMS profiles. ${ }^{2}$ In instances where WAIs living in the U.S. were either obese or overweight, health behaviors (i.e. healthy diet, never smoking, and attempting to exercise) were high, but the rate of physical activity was low.8 Evidence also suggests the prevalence of CVD risk factors among WAIs was predicted by lack of physical activity, stress, and unhealthy diet. ${ }^{9}$ Unhealthy diets were high in salt and refined sugar. ${ }^{10}$ Some choices are beyond the control of WAIs. Immigrant and refugee families have financial difficulties purchasing culturally-specific foods, so they may choose less healthy foods. ${ }^{11}$ Household income is also recognized as a contributing factor to $\mathrm{CV}$ risk factors. Behavior change is difficult when low income and a lack of motivation to engage in health-related behaviors exist. ${ }^{12}$

\section{CVD prevention educational program with text messaging}

Targeted educational interventions are paramount to improving the cardiovascular health of WAIs. However, WAIs may need more support than standard educational programs. Motivational text messaging is one method with the potential to fill a gap between standard educational programs and sustained knowledge and behavioral change in CVD risk factors prevention and control. Several studies have been conducted with use of smart phone and text messaging for cardiovascular risk factor prevention. ${ }^{13-17}$ Studies have been conducted in healthy lifestyle, weight loss, healthy eating, smoking cessation, DMT2 self-management, medication adherence, and physical activity. ${ }^{13-17}$ the efficacy of motivational text messaging in these studies differed in messages, frequency, and duration. Results indicated a positive effect with improving cardiovascular risk reduction. ${ }^{13-17}$ WAIs are a vulnerable group for CVD. The lack of knowledge and behavior of CVD risk factors is a major problem among WAIs. Few studies have examined CVD prevention educational program among WAIs. Studies using motivational text messaging as an enhanced intervention among WAIs for CVD prevention are nonexistent. Thus, the purpose of this study was to examine cardiovascular health knowledge, CVD risk factor behaviors, confidence levels in preparing heart healthy foods, and readiness to change behaviors among adult WAIs. The goal was to promote improved cardiovascular health through risk knowledge, confidence levels in preparing heart health foods, and change to reduce CVD risk factors among WAIs using motivational text messaging as a supplement to the standard educational program. Objectives were to

a. Examine CVD health knowledge, behavior, confidence levels in preparing heart healthy foods, and readiness to change behavior between a $\mathrm{CV}$ education intervention plus motivational text messaging (MTM) and a standard education intervention (SEI)

b. Determine differences in these areas between the two groups.

\section{Method}

\section{Design and setting}

A quasi experimental design was used for this study. The study was approved by the appropriate facilities' Institutional Review Board. The study was conducted in a faith-based organization in the southwestern U.S.

\section{Study population}

Inclusion criteria included: self-identified, English speaking, native WAIs adults 18-74 years old, with or without CVD, and owning a mobile phone. Exclusion criteria were: self- identified WAIs born in the U.S., $<18$ and $>75$ years old, did not own a mobile phone, did not speak English, and/or pregnant.

\section{Procedure}

Participants were recruited through word of mouth, flyers, and church announcements. Participants were randomized to either the standard education intervention (SEI) group or the motivational text messaging (MEM) group.

\section{Pre-intervention}

Demographics and past medical history were collected before the study. Anthropometric measurements (height, weight, waist circumference and BMI and physiological measurements (blood pressure) were also obtained at the beginning of the program. A Likert survey, "My Health Habits", developed by the National, Heart, Lung, Blood Institute (NHLBI).$^{18}$ was completed pre and post intervention.

\section{Intervention}

Both groups received CVD risk factor standard education, two hour sessions weekly for 10 weeks. "My Healthy Habits, a culturally sensitive, evidence based curriculum, developed by the NHLBI18 was used in this study. The curriculum is well recognized and used in diverse communities. The curriculum offers a toolkit of educational materials including manuals, picture card flip charts, recipe books, and risk factor booklets. The program is structured by various heart related topics, including information regarding CVD health knowledge, behavior, confidence levels in preparing healthy foods, and readiness to change. The curriculum was conducted by two nurse practitioners over a ten week period. The MEM group additionally received two motivational text messages weekly during the study period developed specifically for this intervention.

\section{Post-intervention}

Anthropometric and physiological measurements were obtained at the end of the study period. Participants also completed the "My Healthy Habits" survey at the completion of the study.

\section{Measurements}

The demographic questionnaire was specifically developed for this study and included gender, age, educational level, marital status, income level, and country of origin. Anthropometric and physiological measurements were collected using standard methods. The "My Healthy Habits" questionnaire is 21 questions based on cardiovascular risk factors knowledge, behavior in regards to diet, smoking, and physical activity, confidence related to cooking healthy foods, and readiness to change. Each question is structured on Likert scale from 1-8, depending on the type of question. ${ }^{18}$

\section{Statistical analysis}

Descriptive statistics for all study variables were generated overall for demographic and study variables. Categorical data was expressed as percentages. Data between groups was expressed as means and standard deviation (SD) where appropriate. Chi-square was applied 
to categorical variables. T-tests were applied to within and between groups for continuous variables where appropriate. ANOVA and regression analysis was used to determine differences within and between groups. For all analyses, a p-value of $\leq 0.05$ was considered statistically significant. All statistical analyses was conducted using SPSS vs. 24.0. ${ }^{19}$

\section{Results}

There were 75 initial participants. Forty one percent $(n=56)$ completed the program. Four participants were excluded because their phones stopped receiving weekly text messaging. Two participants were not from the required country of origin and 37 were lost to follow up and did provide data post intervention. Of the 38 remaining participants, 16 participants were in the SEI group and 22 were in the MEM group.

\section{Participant characteristics}

The majority of participants were from Nigeria $(68 \%, n=26)$ followed by Ghana $(21 \%, n=8)$. The average age for all participants was 45 years old. There were more males $(63 \%, n=14)$ in the MEM group and more females $(68 \%, \mathrm{n}=11)$ in the SEI group. The majority of participants were married in both groups. More participants had a college education in the MEM group $(54 \%, \mathrm{n}=12)$ compared to grade level education $(31 \%, n=5)$ in the SEI group. The MEM group had higher income levels $(\$ 20-40,000)$ compared to the SEI group $(<\$ 21,000)$.). The majority of participants were nonsmokers $(63 \%$, $\mathrm{n}=14$ in the MEM group versus $44 \%, \mathrm{n}=7$ in the SEI group). Fifty percent $(n=8)$ were overweight in the SEI group compared to $45 \%$ $(n=10)$ in the MEM group. Fifty percent $(n=8)$ were obese in the SEI group compared to $36 \%(\mathrm{n}=8)$ in the MEM group. There were no statistical differences in demographic variables between the groups. Table 1 summarizes these findings.

\section{Medical history}

Medical history for all participants included hypertension 53\% $(\mathrm{n}=20)$, DMT2 11\% $(\mathrm{n}=4)$, hyperlipidemia $45 \%(\mathrm{n}=17)$, and stroke $8 \%(n=3)$. Hypertension was prevalent in both groups. Forty one per cent of participants did not know if they had DMT2. Over fifty percent did not have hyperlipidemia. Forty one percent in the MEM group compared to $21 \%$ in the SEI group did not know if they had a stroke. The medical history was not statistically significant between groups. We also examined medical history by country of origin with no statistically significant results found Table 2 summarizes these findings.

\section{Anthropometric and physiological measurements pre and post intervention}

The overall group had statistically significant change in overall weight, BMI, waist circumference, and systolic blood pressure pre and post intervention. For the MEM group, statistically significant changes were found in weight and systolic blood pressure pre and post intervention. For the SEI group, statistically significant changes were found in weight and waist circumference pre and post intervention. No statistical significance was found between groups in the measurements. Table 3 summarizes these findings.

Table I Characteristics of participants

\begin{tabular}{|c|c|c|c|c|}
\hline & $\begin{array}{l}\text { Total Sample } \\
\mathbf{N}=\mathbf{3 8}\end{array}$ & $\begin{array}{l}\text { MEM Group } \\
N=22\end{array}$ & $\begin{array}{l}\text { SEI Group } \\
N=16\end{array}$ & P Value \\
\hline County of Origin & $\mathrm{N}(\%)$ & $N(\%)$ & $\mathrm{N}(\%)$ & 0.11 \\
\hline Ghana & $8(2 I . I)$ & $3(13.6)$ & $5(31.3)$ & \\
\hline Nigeria & $26(68.4)$ & $17(77.3)$ & $9(56.3)$ & \\
\hline Togo & $2(5.3)$ & $0(0.0)$ & $2(12.5)$ & \\
\hline Tanzania & $2(5.3)$ & $2(9.1)$ & $0(0.0)$ & \\
\hline Age: Mean (SD) & $45.1(18.2)$ & $46.2(17.2)$ & 43.5 (19.9) & 0.35 \\
\hline Gender & & & & 0.1 \\
\hline Male & $19(50.0)$ & $14(63.6)$ & $5(31.3)$ & \\
\hline Female & $19(50.0)$ & $8(36.3)$ & II (68.8) & \\
\hline Marital Status & & & & 0.3 \\
\hline Married & 18 (47.4) & $10(45.5)$ & $8(50.0)$ & \\
\hline Single & $9(23.7)$ & $5(22.7)$ & $4(25.0)$ & \\
\hline Divorced & $6(15.8)$ & $2(9.1)$ & $4(25.0)$ & \\
\hline Widow & $3(7.9)$ & $3(13.6)$ & $0(0.0)$ & \\
\hline Widower & $2(5.3)$ & $2(9.1)$ & $0(0.0)$ & \\
\hline
\end{tabular}


Table Continued..

\begin{tabular}{|c|c|c|c|c|}
\hline & $\begin{array}{l}\text { Total Sample } \\
\mathbf{N}=\mathbf{3 8}\end{array}$ & $\begin{array}{l}\text { MEM Group } \\
\mathbf{N}=22\end{array}$ & $\begin{array}{l}\text { SEI Group } \\
N=16\end{array}$ & P Value \\
\hline Education Level & & & & 0.15 \\
\hline I-6th grade & $3(7.9)$ & I (4.6) & $2(12.5)$ & \\
\hline $7-12$ th grade & $9(23.7)$ & $4(18.2)$ & $5(31.3)$ & \\
\hline Undergraduate & $6(15.8)$ & $2(9.1)$ & $4(25.0)$ & \\
\hline Bachelor's & $15(39.5)$ & $12(54.6)$ & $3(18.8)$ & \\
\hline Master's & $2(5.3)$ & $2(9.1)$ & $0(0.0)$ & \\
\hline Graduate degree & $3(7.9)$ & I (4.6) & $2(12.5)$ & \\
\hline Income Level & & & & 0.42 \\
\hline$\$ 0-20,000$ & II (29.0) & $4(18.2)$ & $7(43.8)$ & \\
\hline$\$ 21,000-40,000$ & $12(31.6)$ & $8(36.4)$ & $4(25.0)$ & \\
\hline$\$ 41,000-60,000$ & $7(18.4)$ & $5(22.7)$ & $2(12.5)$ & \\
\hline$\$ 6 I, 000-80,000$ & $4(10.5)$ & $3(13.6)$ & I (6.3) & \\
\hline$\$ 81,000-100,000$ & $3(7.9)$ & I (4.6) & $2(5.3)$ & \\
\hline Over $\$ 100,000$ & I (2.6) & I (4.6) & $0(0.0)$ & \\
\hline Smoking Status & & & & 0.36 \\
\hline Yes & $8(21.1)$ & $3(13.6)$ & $5(31.3)$ & \\
\hline No & $21(55.3)$ & 14 (63.6) & $7(43.8)$ & \\
\hline Former & $9(23.7)$ & $5(22.7)$ & $4(25.0)$ & \\
\hline BMI & & & & 0.19 \\
\hline Normal & $4(10.5)$ & $4(18.2)$ & $0(0.0)$ & \\
\hline Overweight & $16(42.1)$ & $10(45.5)$ & $8(50.0)$ & \\
\hline Obese & I 8 (47.4) & $8(36.4)$ & $8(50.0)$ & \\
\hline
\end{tabular}

Table 2 Medical history of CVD and risk factors by group and country of origin

\begin{tabular}{|c|c|c|c|c|c|c|c|c|c|}
\hline & $\begin{array}{l}\text { Total } \\
\text { Sample } \\
\mathbf{N}=\mathbf{3 8}\end{array}$ & $\begin{array}{l}\text { SEI Group } \\
\mathbf{N}=22\end{array}$ & $\begin{array}{l}\text { MEM Group } \\
N=16\end{array}$ & PValue & $\begin{array}{l}\text { Ghana } \\
(\mathbf{N}=\mathbf{8})\end{array}$ & $\begin{array}{l}\text { Nigeria } \\
(N=26)\end{array}$ & $\begin{array}{l}\text { Tanzania } \\
(\mathbf{N}=\mathbf{2})\end{array}$ & $\begin{array}{l}\text { Togo } \\
(\mathbf{N}=2)\end{array}$ & P Value \\
\hline HTN & & & & 0.01 & $N(\%)$ & $N(\%)$ & $N(\%)$ & $\mathrm{N}(\%)$ & 0.42 \\
\hline Yes & $20(52.6)$ & $16(72.7)$ & $4(25.0)$ & & $2(25.0)$ & $16(6 \mid .5)$ & I (50.0) & I (50.0) & \\
\hline No & $17(44.7)$ & $6(27.3)$ & II (68.8) & & $6(75.0)$ & $9(34.6)$ & I (50.0) & I (50.0) & \\
\hline Don't Know & I (2.6) & $0(0.0)$ & I (6.3) & & $0(0.0)$ & I (3.9) & $0(0.0)$ & $0(0.0)$ & \\
\hline Diabetes & & & & 0.11 & & & & & 0.22 \\
\hline Yes & $4(10.5)$ & I (4.6) & $3(18.6)$ & & $2(25.0)$ & $2(7.7)$ & $0(0.0)$ & $0(0.0)$ & \\
\hline No & $23(60.5)$ & $12(54.6)$ & II (68.8) & & $5(62.5)$ & $16(64.5)$ & $0(0.0)$ & $\begin{array}{l}2 \\
(100.0)\end{array}$ & \\
\hline Don't Know & II (29.0) & $9(40.9)$ & $2(12.5)$ & & I (I2.5) & $8(30.8)$ & $2(100.0)$ & $0(0.0)$ & \\
\hline Hyperlipidemia & & & & I & & & & & 0.76 \\
\hline Yes & 17 (44.7) & $10(45.5)$ & 7 (43.8) & & $5(62.5)$ & $10(38.5)$ & I (50.0) & I (50.0) & \\
\hline No & $21(55.3)$ & $12(54.6)$ & $9(56.3)$ & & $3(37.5)$ & $16(61.5)$ & I (50.0) & I (50.0) & \\
\hline Don't Know & $0(0.0)$ & $0(0.0)$ & $0(0.0)$ & & $0(0.0)$ & $0(0.0)$ & $0(0.0)$ & $0(0.0)$ & \\
\hline Stroke & & & & 0.54 & & & & & 0.8 \\
\hline Yes & $3(7.9)$ & $2(9.1)$ & I (6.3) & & $0(0.0)$ & $3(11.5)$ & $0(0.0)$ & $0(0.0)$ & \\
\hline No & $22(57.9)$ & II (50.0) & II (68.8) & & $4(50.0)$ & $15(57.7)$ & I (50.0) & $\begin{array}{l}2 \\
(100.0)\end{array}$ & \\
\hline Don't Know & $13(34.2)$ & $9(40.9)$ & $4(25.0)$ & & $4(50.0)$ & $8(30.8)$ & I (50.0) & $0(0.0)$ & \\
\hline
\end{tabular}


Table 3 Anthropometric and physiological measurements

\begin{tabular}{|c|c|c|c|c|c|c|c|c|c|c|}
\hline & $\begin{array}{l}\text { Total } \\
\text { Sample } \\
\mathbf{N}=\mathbf{3 8}\end{array}$ & & & $\begin{array}{l}\text { MEM } \\
\text { GROUP } \\
(\mathbf{N}=22)\end{array}$ & & & $\begin{array}{l}\text { SEI } \\
\text { GROUP = } \\
\text { l6) }\end{array}$ & & & \\
\hline Weight & Pre & Post & $\begin{array}{l}\mathbf{P} \\
\text { Value }\end{array}$ & Pre & Post & $\begin{array}{l}\mathbf{P} \\
\text { Value }\end{array}$ & Pre & & Post & $\begin{array}{l}\mathbf{P} \\
\text { Value }\end{array}$ \\
\hline Mean (SD) & $193.0(31.8)$ & $189.0(27.6)$ & 0.003 & I $88.4(26.0)$ & I 85.7 (23.2) & 0.04 & I97.3 (36.3) & $\begin{array}{l}193.4 \\
(33.1)\end{array}$ & & 0.02 \\
\hline \multicolumn{11}{|l|}{ BMI } \\
\hline Mean (SD) & $31.3(5.1)$ & $30.1(4.9)$ & 0.009 & $30.4(5.0)$ & $29.5(5.3)$ & 0.06 & $32.1(5.1)$ & & $30.9(4.3)$ & 0.08 \\
\hline \multicolumn{11}{|l|}{ Systolic } \\
\hline Mean (SD) & I28.4 (I6.6) & $122.4(9.8)$ & 0.001 & |3I.| (16.8) & I23.4 (8.8) & 0 & $125.9(16.3)$ & & I2I.I (II.3) & 0.31 \\
\hline \multicolumn{11}{|l|}{ Diastolic } \\
\hline Mean (SD) & $73.9(9.1)$ & $71.8(6.8)$ & 0.79 & $73.1(8.5)$ & $73.0(8.5)$ & 0.87 & $74.6(9.7)$ & & 70.1 (6.8) & 0.6 \\
\hline \multicolumn{11}{|l|}{ Waist } \\
\hline \multicolumn{11}{|c|}{ Circumference } \\
\hline Mean (SD) & $40.6(4.3)$ & $39.9(4.5)$ & 0.003 & $40.5(4.7)$ & $39.9(4.8)$ & 0.07 & $40.6(3.9)$ & & $39.8(4.2)$ & 0.03 \\
\hline
\end{tabular}

\section{Outcome measures}

CVD Risk Factor Knowledge, Behavior, Confidence in Preparing Healthy Foods, and Readiness to Change. Results indicated statistically significant results within groups between pre and post intervention for CVD risk factor, $(\mathrm{p}=0.000)$, behavior $(\mathrm{p}=0.000)$, confidence in preparing healthy foods $(\mathrm{p}=0.000)$, and readiness to change $(\mathrm{p}=.001)$. There was no difference, however, between SEI or MEM groups in CVD risk factor, $(\mathrm{p}=0.92)$, behavior $(\mathrm{p}=.81)$, confidence in preparing healthy foods $(\mathrm{p}=0.50)$, and readiness to change $(\mathrm{p}=.99)$. Figures $1-4$ illustrate the difference by group in pre and post intervention scores.

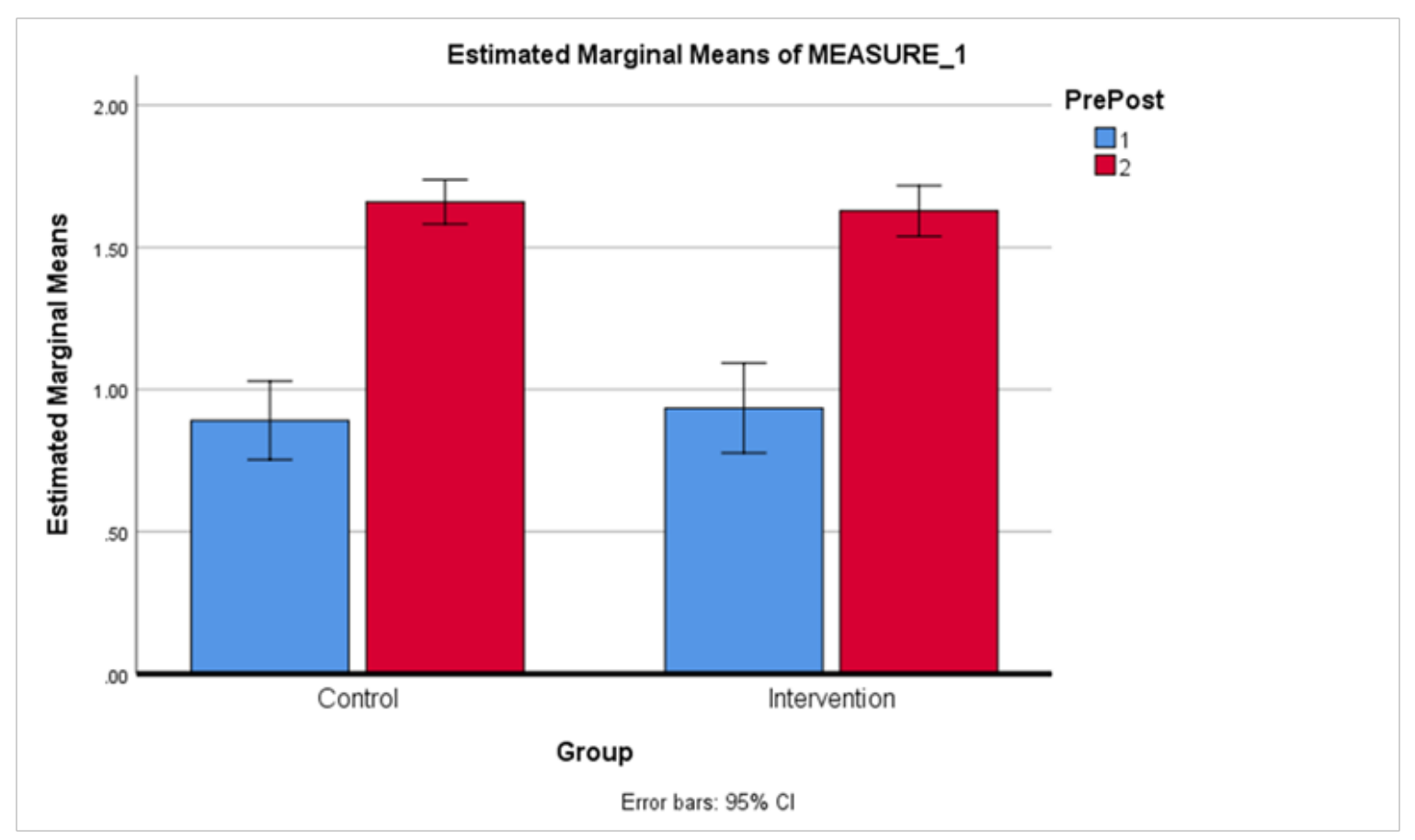

Figure I CVD risk factor knowledge pre and post intervention by group. 


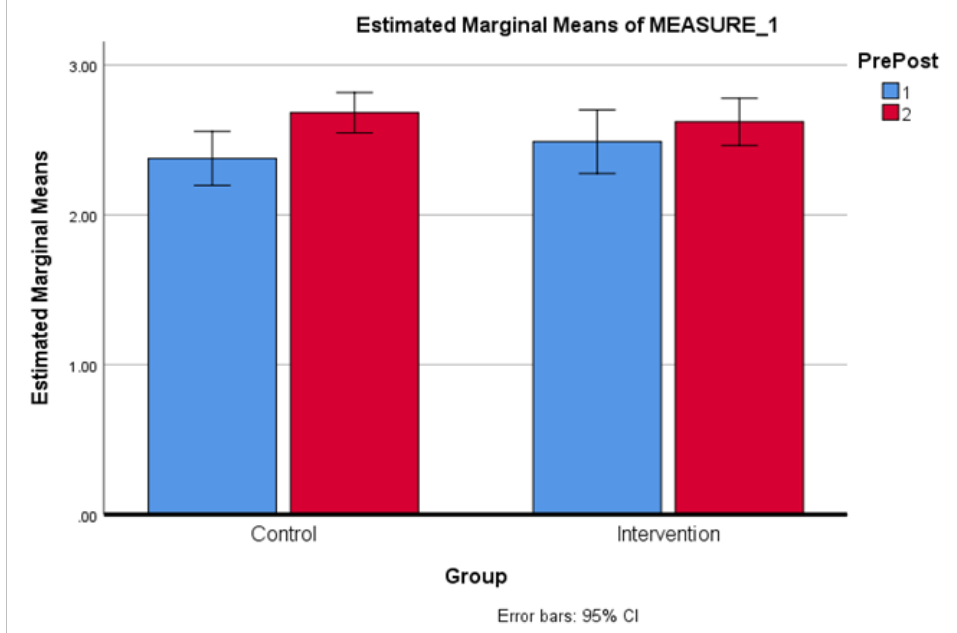

Figure 2 CVD risk factor behavior pre and post intervention by group.

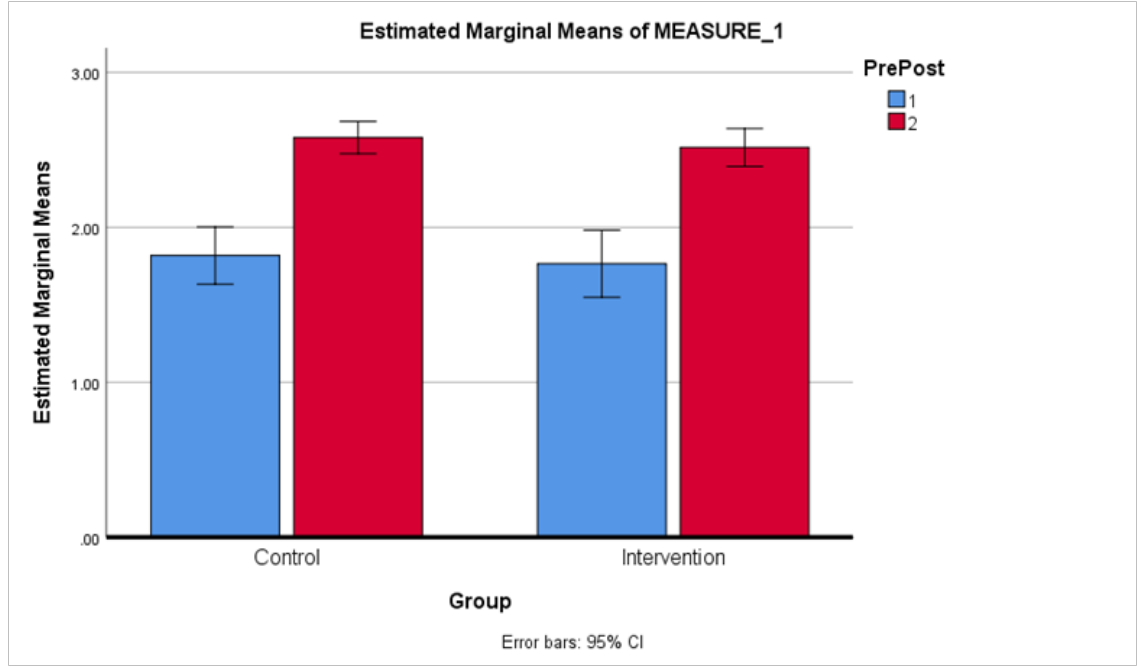

Figure 3 Confidence levels pre and post intervention by group.

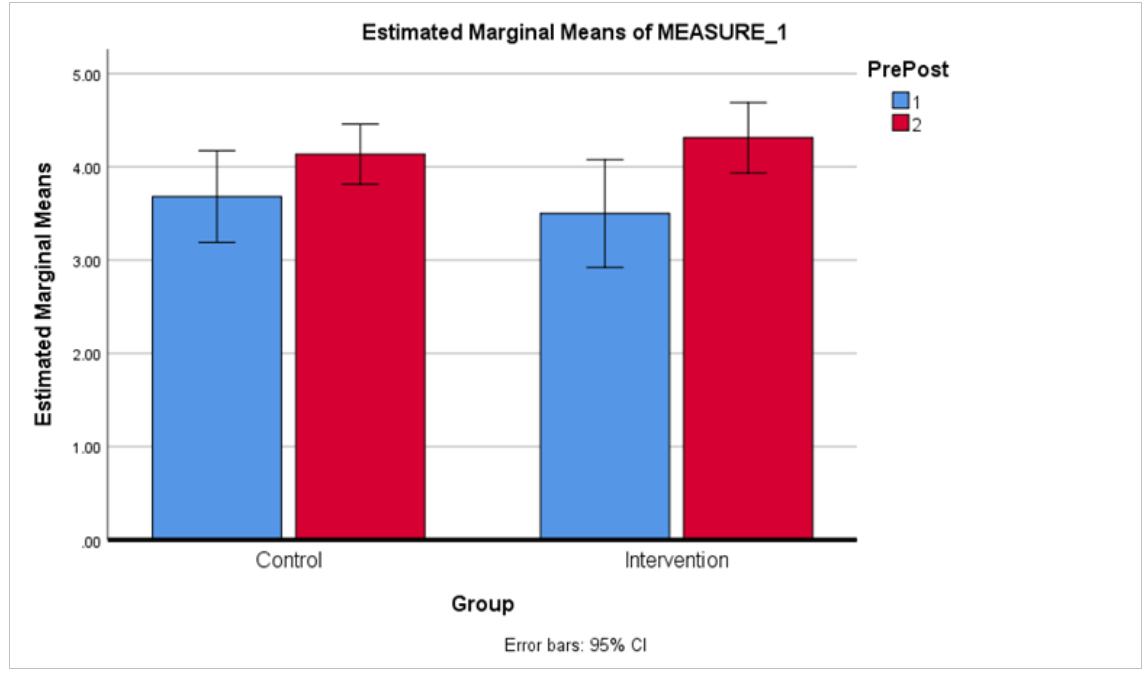

Figure 4 Readinesses to change pre and post intervention by group. 


\section{Discussion}

This was the first study to evaluate a CVD prevention education program plus motivational text messaging among WAIs. Statistically significant change was noted in anthropometric measurements of weight, BMI, systolic blood pressure, and waist circumference for the overall group. Although statistically significant improvement was noted in all areas within groups between pre and post intervention performance, there was no difference between groups in the areas of CVD risk knowledge, behavior, confidence to prepare healthy foods, and readiness to change. Our findings were in sharp contrast to previous studies that motivational text messaging can enhance standard education programs. Studies have shown text messages can be used to motivate participants, send reminders, and encourage positive decisions making that impacted their behavior. ${ }^{13-17}$ Dobson et al. ${ }^{14}$ found motivational text messages that linked the behaviors of the participants to their health, resulted in change for eating behaviors and smoking cessation. Chow et al. ${ }^{18}$ used mobile text messaging to encourage lifestyle changes among patients with coronary heart disease. The results indicated a moderate improvement in BMI, blood pressure, low density lipid, and smoking statues..$^{18}$

Our findings did not show text messaging made a difference in risk factor knowledge, behavior, confidence in preparing healthy foods, or readiness to change. Muench \& Baumel $^{19}$ emphasized that text messaging is less desirable in motivating individuals, it is an insecure method for delivery of health information, is expensive, and it may be difficult to comprehend complex information..$^{20,21}$ Additionally, there are gender differences in risk factor control and behaviors. Studies show WAI men were aware of the risk factors, but this has not shown to translate to perceived risk5 Studies have also shown that although WAI men were aware of their hypertensive status, women achieved better control. ${ }^{6}$ Moreover, there is the issue of language and culture. It is not known if text messaging is culturally acceptable among WAIs. Furthermore, WAIs place more value on family rather than individual pursuits. Studies have also shown those who understood English were more likely to engage in protective behaviors. ${ }^{5}$ It may be that text messaging is not the most appropriate method for CVD prevention.

\section{Limitations}

There were several limitations of this study. The sample size was small. There was no control group. Participants were not blinded to investigators. Participants were also recruited from a single faithbased organization, limiting the generalizability of findings. Selfreport by participants was also used as the outcome measure, which may have been under or over-reported by participants, influencing bias The attrition rate for program completion was high and needs to be explored in future studies. Investigator bias may also have impacted the study. The investigator was a member of the faith based organization and personally knew many of the participants. While every effort was made to protect the rigor of the study, investigator bias cannot be excluded. However, our study adds to the literature by providing an analysis of CVD prevention education plus text messaging among WAIs.

\section{Conclusion}

The implications of this study are that WAIs are a vulnerable group for CVD. Intervention studies for this group are scarce. Our results suggest that standard education for CVD prevention is effective and suitable for WAIs. Text messaging may not enhance these endeavors. Additionally, country of origin, social and cultural belief systems need to be considered in future studies among WAIs. Future research with larger sample size from multiple sites is needed to further investigate best practice for CVD prevention among this population.

\section{Funding details}

None.

\section{Acknowledgements}

None.

\section{Conflicts of interest}

The authors declare that there is no conflict of interest.

\section{References}

1. Pew Research Center. African immigrant population in U.S. steadily climbs. FactTank: news in the numbers. 2017. 2019.

2. O'Connor MY, Thoreson CK, Ricks M, et al. Worse cardiometabolic health in African Immigrant men than African American men: Reconsideration of the healthy immigrant effect. Metab Syndr Relat Disord. 2014;12(6):347-353.

3. International Diabetes Federation. Africa. IDF Diabetes Atlas. 2017.

4. Commodore-Mensah Y, Sampah ME, Berko C, et al. The Afro-Cardiac Study: Cardiovascular disease risk and acculturation in West African immigrants in the United States: rationale and study design. Journal of Immigrant \& Minority Health. 2016;18(6):1301-1308.

5. Boateng D, Wekesah, Browne JL, et al. Knowledge and awareness of and perception towards cardiovascular disease risk in sub-Saharan Africa: a systematic review. PloS One. 2017;12(2):e289264.

6. Kayima J, Wanyenze RK, Katamba A, et al. Hypertension awareness, treatment, and control in Africa: a systematic review. BMC Cardiovascular Disorders. 2013;13(54).

7. Sewali B, Harcourt N, Everson-Rose S, et al. Prevalence of cardiovascular risk factors across six African immigrant groups in Minnesota. $B M C$ Public Health. 2015;15(1):411-411.

8. Sumner AE, Duong MT, Bingham BA, et al. Glycated albumin identifies prediabetes not detected by hemoglobin A1c: The Africans in America Study. Clinical Chemistry. 2016;62(11):1524-1532.

9. Sabzmakan L, Morowatisharifabad MA, Mohammadi E, et al. Behavioral determinants of cardiovascular diseases risk factors: A qualitative directed content analysis. ARYA Atherosclerosis. 2014;10(2):71-81.

10. Anand SS, Hawkes C, de Souza RJ, et al. Food consumption and its impact on cardiovascular disease: Importance of solutions focused on the globalized food system: A report from the workshop convened by the World Heart Federation. J Am Coll Cardiol. 2015;66(14):1590-1614

11. Hardcastle SJ, Hancox J, Hattar A, et al. Motivating the unmotivated: How can health behavior be changed in those unwilling to change? Frontiers in Psychology. 2015;6:835.

12. Lemstra M, Rogers M, Moraros J. Income and heart disease: Neglected risk factor. Can Fam Physician. 2015;61(8):698-704.

13. Militello L, Melnyk BM, Hekler E, et al. Automated behavioral text messaging and face-to-face intervention for parents of overweight or obese preschool children: Results from a pilot study. JMIR mHealth and uHealth. 2016;4(1):e21. 
14. Dobson R, Whittaker R, Jiang Y, et al. Text message-based diabetes self-management support (SMS4BG): Study protocol for a randomized controlled trial. Trials. 2016;17:179.

15. Hall AK, Cole-Lewis H, Bernhardt JM. Mobile text messaging for health: A systematic review of reviews. Annu Rev Public Health. 2015;36:393415 .

16. Kinnafick F, Thøgersen-Ntoumani C, Duda J. The effect of need supportive text messages on motivation and physical activity behavior. $J$ Behav Med. 2016;39(4):574-586.

17. Shapiro JR, Koro T, Doran N, et al. Text4Diet: A randomized controlled study using text messaging for weight loss behaviors. Prev Med. 2016;55(5):412-417.
18. Chow CK, Redfern J, Hillis GS, et al. Effect of lifestyle-focused text messaging on risk factor modification in patients with coronary heart disease: A randomized clinical trial. JAMA: Journal of the American Medical Association. 2015;314(12):1255-1263.

19. Muench F, Baumel A. More than a text message: Dismantling digital triggers to curate behavior change in patient-centered health interventions. J Med Internet Res. 2017;19(5):e147.

20. National Heart, Lung, and Blood Institute. Community health worker health disparities initiative: My Healthy Habits Survey. 2012a.

21. IBM SPSS Statistics for Windows, Version 24.0. Armonk, NY: IBM Corp; 2016. 